\title{
Can Wiki Be Used to Facilitate Critical Thinking? : A Qualitative Approach
}

\author{
http://dx.doi.org/10.3991/ijep.v2i4.2247 \\ W.W. Goh \\ Taylor's University, Kuala Lumpur, Malaysia
}

\begin{abstract}
The main purpose of this study is to investigate the use of wiki for the development of critical thinking skills of students in higher education. This study seeks to explore the learning experiences of students in utilizing wiki to facilitate the development of critical thinking skills. Wiki was introduced to 19 postgraduate students taking the "Studying at Masters Level and Research Methods" module in one of the post-1992 university in the United Kingdom. They used the designed wiki as a learning tool and their responses towards wiki were explored based on the discussions and interaction in the wiki pages. At the end of the term, questionnaires and a focus group were used to collect their perceptions. The results show that critical thinking happens during the individual construction of knowledge when they reflect on and evaluate information. However, students did not always show their critical and analytical skills in collaborating and discussing in the wiki due to the low level of interaction.
\end{abstract}

Index Terms-Critical thinking, Educational technology, Electronic learning, Learning technology, Web 2.0, Wiki.

\section{INTRODUCTION}

The use of Web 2.0 technologies in Higher Education Institutions (HEI) is increasing [1]. Online technologies are permeating the education arena worldwide and many HEIs are turning to e-learning technologies to improve the quality of learning by means of access to resources, interaction and communication. Due to the importance of critical thinking skills as a life skill for graduates to survive in the competitive world [2], it is therefore valuable to explore whether Web 2.0 technologies can assist in facilitating the critical thinking skills of students.

Many higher education institutions and e-learning bodies are focusing on the development and implementation of online technologies to enhance students' learning environments. One example is researching e-learning and pedagogical issues by the Joint Information Systems Committee (JISC) [3]. JISC is principally concerned with exploring the experiences of practitioners and students in using online technologies. It investigates the effectiveness of e-learning and examines the students' participation and engagement in using e-learning technologies. Nevertheless, there is little empirical evidence on the learning experiences of students in using wiki to facilitate critical thinking skills. Hence, the purpose of this study is to explore the learning experiences of students in a post1992 university in the United Kingdom utilizing wiki during their learning process and thus understand how this Web 2.0 tool might develop and enhance the critical thinking skills of students in Higher Education. The research question for this study is "how effective is the use of this Web 2.0 tool to develop critical thinking skills of students?"

This paper will first discuss the role of critical thinking skills in higher education. The main features of wiki are examined in detail as it is the Web 2.0 technology chosen for this study. This is followed by an overview of the background of the study and research method. Next, the learning experiences of students are analysed and elaborated on in detail. Lastly, the discussions and implications are presented.

\section{LITERATURE REVIEW}

\section{A. Role of Critical Thinking Skills in Higher Education}

Over the last decade, critical thinking has been frequently argued to be at the heart of a university education [4]. Higher education continues to have a unique role in producing students with the higher order skills of evaluation, critical analysis and reflection, synthesis, problem solving, creativity and thinking across discipline boundaries.

Critical thinking has become a highly valued learning outcome and is a central aim for higher education leading to life-long learning and increasing employability. It is a common objective of various disciplines and a goal that most courses aspire to achieve.

Higher education institutions are encouraged to embed critical thinking in curriculum development across undergraduate and post-graduate studies [2]. It is important to cultivate the generic skills of students in employing evidence-based reasoning and making critical judgments and evaluations in order to increase the employability of the students. It is stated in Newman et al. [2] that graduates normally fail to meet the expectations of employers due to a lack of critical thinking skills. They do not have the ability to compare and evaluate information obtained from different sources, to synthesise information and thus create new knowledge in a particular subject discipline. As such, this skill is becoming increasingly important as curricula clearly state the development of critical thinking skills as a learning outcome.

Therefore, tutors play a vital role in promoting critical thinking skills in the higher education classroom. They need to encourage students to question, think critically and solve problems during active learning activities. However, evidence shows that many tutors are neither taught to think critically nor taught how to get their students to think critically [5]. Tutors need to engage students in 
applying critical thinking skills using course content material with the help of online technologies.

\section{B. Main Features of Wiki}

Wiki is widely used to foster the learning of students in higher education and has the potential to enhance the learning experience of students [6], [7]. Some literature asserts that wiki is a useful tool for pooling and sharing information among students and offers a place for students to get together virtually to discuss, learn and personalise their learning experience [8], [9]. McMullin [10] agrees that wiki offers a set of tools for social reflection, collaboration and construction of knowledge. It allows learners to build resources collaboratively, as it has a low technological barrier, but rich and flexible features. Students value the collaboration opportunity to learn together and discuss ideas amongst each other [11].

Learning occurs through the exchange and sharing of information and opinions in a community using wiki [12]. Wheeler et al. [7] pointed out that wiki can deepen students' engagement in the learning process and encourage the co-construction of knowledge among peers. Furthermore, the use of wiki facilitates high-level thinking skills among students. In order to encourage students to engage critically with materials and sources, group tasks were designed to facilitate critical judgments [13]. Lombard [14] suggested that the effectiveness of wiki in facilitating critical thinking skills is dependent on the students' ability to validate and explain data and stand up to criticism. However, Anderson \& Krathwohl [15] pointed out that the majority of students engage in activities related to the application of knowledge rather than the evaluation of knowledge when they interacted with their peers in wiki. In order to engage students to think critically, they suggested that learning activities need to facilitate critical judgment and that assessment criteria need to involve the analysis and synthesis of information.

Whilst some studies emphasize the collaboration and interactivity of wiki, others focus on using wiki to support reflection. Reflective learning allows students to reflect on their own knowledge and make it explicit through collaboratively building of resources using wiki [16]. As mentioned by Hall \& Conboy [17], wiki helps to promote students as reflective practitioners. Students use wiki to build electronic portfolio collections to support their reflective thinking [18]. This increases their awareness of what is learned and encourages students to make their knowledge explicit and visible. As such, wiki is suited to support the process of coached reflection and increasing students' reflecting learning. Hence, reflective activity could be helpful to enhance students' critical thinking skills.

\section{RESEARCH DESIGN}

\section{A. Background of Study}

19 students, who took part in the "Studying at Masters Level and Research Methods" module, voluntarily participated in this study and all contributions were anonymous. They were all mature students ranging in age from 23 to 55 years. Consent forms were distributed to all of them to receive their consent for participation. All the students' names are pseudonyms in order to protect their identities and are represented by their initials.
Students were required to review articles and share the references on the wiki. They also had to prepare a weekly seminar preparation question and post the answer on the common page in the wiki. Basically, all the questions in the seminar preparation were based on the topic for the coming lecture so that the students were fully prepared before attending the next class. The main reason for introducing wiki to this module was to enable the students to collaborate on a weekly seminar preparation task, to compare and contrast their ideas with peers and to develop the ability of critical analysis through interaction using wiki. This allowed students to have opportunities to debate and discuss with their peers at any time of day.

Students were assessed throughout the 12 weeks on their participation and involvement in the wiki and $10 \%$ of the overall weighting for the coursework was based on this. Besides demonstrating their knowledge of the topic, students were awarded marks for their critical analysis and evaluation of their peers' posts and for the quality of synthesising the materials' sources from credible sources. It is also important that they showed evidence of collaboration and interaction, rather than it appearing to be the work of separate individuals.

\section{B. Research Methods}

A variety of data collection methods were used to achieve an appropriate level of triangulation [19]. Data was collected through a focus group, questionnaires and analysis of the content of the wiki pages. Eight students voluntarily participated in the one hour focus group discussion to collect some in-depth perceptions about their participation in the wiki. To follow up the focus group in this study, a questionnaire was used to obtain more detail from all the students as evidence to support judgements of how students used wiki during their learning. The questionnaire included a five-point Likert Scale (strongly agree, agree, neutral, disagree, strongly disagree) questions and open ended comments to elicit students' perceptions.

PBworks.com was used as a platform for this study. Wiki pages were used to track the development and progress of the students in using the wiki by utilising the history feature of PBworks.com. When analysing students' contributions on the wiki, all the postings were categorised into arguments, backing up arguments and supporting statements in order to find out whether the students had applied critical and analytical skills in answering all the questions.

A thematic analysis [20] was performed on the entire interview transcript to look for the perceptions of the learners in using the wiki. The learning experiences of students in using the wiki are analysed and explained in the following section.

\section{RESULTS AND FINDINGS}

The main purpose of introducing wiki in this study is to explore the students' learning experiences in using wiki as a learning tool to facilitate the development of critical thinking skills.

This cohort of students was very diverse with a variety of experiences, backgrounds and knowledge. It consisted of a mixture of students from developed and developing countries with different learning styles, cultures and prior knowledge in IT. The information technology background 
of the students was also mixed. However, all of them had Computing degrees. As a result, they had studied programming, basic computer usage and considered their proficiency in IT as satisfactory. They each had an IT background of at least 5 years and had used VLEs before. Nevertheless, none of them were familiar with using wiki. They had not participated in the wiki before but had used Wikipedia as a reference resource. Some of them had used other interactive tools like forums and discussion boards before.

Students were expected to construct their own knowledge and develop tacit knowledge rather than being a passive receiver. The role of the tutor here is to facilitate the process of analysis, construction and confirmation of meaning and understanding through a teaching presence. Key findings on the learning experiences of students in using wiki are presented below.

\section{A. Low Level of Interaction}

Students were requested to develop and demonstrate critical thinking skills in their work because one of the lessons was on "How to think critically". There was a common page for the students to answer the weekly seminar preparation questions and to exchange ideas. They were expected to share their ideas based on evidence, to compare and contrast their points with their peers and to challenge their peers' answers in the common page.

However, between week 1 to week 7 , the analysis showed that the majority of the students just wrote their own ideas without linking or connecting their ideas with their peers'. They did not compare and contrast their ideas with other ideas. They seldom critically analysed or critically evaluated others' points of view. They just answered the questions descriptively. It was like a content page for answers without any critical analysis.

The students simply searched for answers and wrote them in the wiki without thinking and constructing the knowledge themselves. Students reported that the low level of interaction was due to information overload: the amount of information students were expected to read and absorb was too much so the students lost interest. As the wiki in this study was for a group of 19, the amount of content produced grew exponentially. Thus it became very hard for any individual learner to make meaningful connections with others' work simply because of the sheer volume of content. They just cannot focus on reading a few contributions. The students were confused and they just read the last two contributions so that they were justified in saying that they had looked at their peers' contributions. It might work better in a smaller group because it would be easier for them to discuss and interact together within the group. Not having to read so many contributions would save time.

"SM: I think we were very large group to be contain in a wiki for something we being marked on".

One student acknowledged that: "Students can discuss together in the group regarding whatever they have experienced. It is hard to read all the contributions when reached 7 or 10 students' contributions".

\section{B. Triggering Questions Are Essential to Facilitate Critical Thinking}

At the early stage, it was found that the students did not put much effort into participating in discussions, interaction and communication with peers. They did not come up with the answers collaboratively although a small group of students did take part in the discussions. This implies that collaborative learning was less visible.

According to Garrison, Anderson \& Archer [21], it is important to promote open communication among students through support in acknowledging individual contributions and reacting to the specific content of the messages. Nevertheless, the students rarely responded and reacted to their peers' content. One of the students expressed that the problem they had was that most of the students just wrote their own ideas without providing any way for other students to respond or interact. The student just write "I agree...." and "I disagree..." with their peers" ideas and posts without any justification. This shows that they did not ask intriguing, open- ended questions in order to keep the discussion flowing. It was hard for them to think deeply and come up with answers collaboratively.

Some students suggested that the tutor or their peers should post some controversial questions so that the interaction could be kept going. This would encourage the students to continue to interact.

From week 8 onwards, it was noticed that a minority of the students did start to interact with their peers and learn from one another. The dynamic learning process occurred when they collaborated with each other. Different ideas emerged during the interaction. The students started to receive responses and new ideas from their peers and tutor. The reason for this change was due to the intriguing and open ended questions posted by their peers and tutor. This shows the importance of triggering debate by posing interesting questions for students to answer. The level of engagement with each other increased as the students were able to answer the questions posted by their peers and keep the discussion going.

Therefore, the study has found that when the students answered "I agree..." or "I disagree....", they had created a kind of "dead end" situation, which was unable to create an engaging environment. Interaction will occur if students prompt questions and probing for other students to answer. Hence, students should be encouraged to post "trigger" messages rather than "response" messages. If students post only "response" messages, it will more likely end the discussion than "trigger" questions. This shows that "trigger" messages play an essential role in online communities.

\section{Different Kinds of Critical Thinking Observed}

From week 9 to week 11, from the analysis of the wiki pages, there was increasing evidence of collaboration and interaction. The students read their peers' work and half of the class had put some effort into participating in the discussion, interaction and communication with peers. The tutor also participated in the wiki and invited constructive criticisms in order to keep the discussion going.

It was noticed that a few students started to demonstrate their critical thinking skills using the wiki. Several kinds of critical thinking were identified in their interactions in the wiki pages. The students showed evidence of reading one another's posts and sharing their views. Some of them 
showed the skill of critical thinking and critical analysis in the use of theory and evidence. There was evidence of collaboration and interaction among the students. These students had put the effort into participating in discussing and interacting with peers. They came up with answers collaboratively in the weekly seminar preparation tasks. Some of the students also expressed that they agreed with their peers' views and justified their points. They were able to apply the concepts and theories to their own experiences.

It was noticed that certain students provided evidence to support their arguments in their answers with reliable and credible resources to make their ideas stronger. Some of them related the answers back to concepts and theories. They constructed ideas using the answers provided by other peers, they interpreted the answers and connected with their personal experience in order to generate new knowledge.

Based on the analysis of the wiki pages, the process of critical thinking can be summarised as follows: A student read an existing wiki page and he disagreed with it (a trigger event), then he went to search for a related paper (resource searching) and read the paper (knowledge acquisition). He then compared his view with the existing wiki page to come up with an argument (knowledge construction) and finally wrote the answers in the wiki (knowledge sharing). Construction of knowledge (critical thinking) occurs when there is an assimilation of new information into existing ideas.

From the analysis of wiki pages, it was observed that critical thinking has happened in the follow scenarios:

1) Critical Thinking Through Incorporating Other's Ideas

Some students expressed their agreement with their peers' views and justified their points. They critically evaluated and analysed their peers' posts. Fig. 1 illustrates how students incorporated others' ideas.

\section{2) Critical Thinking Through Reflection}

From the findings, some students shared their own views related to their personal experience. They made some effort to analyse reasons from their own point of view. Tacit knowledge was developed as the students linked the learning content with their personal experiences. From the wiki page analysis in fig. 2, the students were sharing their understanding and experiences together. They reflected on the course material and related it to their real life experiences.

\section{3) Critical Thinking Through Synthesising Credible} Information

Some of the students showed the skill of critical thinking and critical analysis in the use of theory and evidence. Fig. 3 demonstrates that they provided evidence to support their argument in the answer with reliable and credible sources.

4) Critical Thinking Through In Depth Explanation of a Point

Lombard [14] suggested that the effectiveness of wiki in facilitating critical thinking skills depends on the students' ability to validate and explain data and stand up to criticism. Fig. 4 shows that some students explained their point in detail to show their understanding of certain points.
JF:

"I came across these quotes.

"If a project has no risks, don't do it" \& "Risk management is project management for adults".

So in my view one of the main key issues is that it important to under take a risk assessment in order to identify the risks and quantify their potential effects during the design phase of the project.

Another important aspect is that your projects are unique and may be hard for it to run to plan, so keep an open mind and be prepared to change the design, involve your supervisor at an early stage."

DB:

"I agree with JF about the fact that you have to be prepared for change. This would involve a contingency plan and the management of risk does not allow contingency to be "optional". (Techrepublic.com, 2007). I would argue against JF that it may be possible that your project is not unique though.... surely this is an assumption?"

Figure 1. Critical thinking through incorporating other's ideas

Example by DA:

"I think based on my experience; when you choose an experimental project the most important key is to know where to go for help if you struggle in implementing the experiment project, sometimes take a long time for a technical issue to be solved, which might take a lot of time in overall project."

Figure 2. Critical thinking through reflection

"For such projects to be considered as research, rather than only an illustration of technical prowess, they should demonstrate not just technical skills but also academic qualities such as analysis, explanation, argument, justification and critical evaluation. They must also contribute to the knowledge in some way." (Oates, 2006).

The above suggests that one of the issues with a Design and Creation project is the possibility of the researcher getting too involved in a programming assignment without enough attention to research and maybe putting in a lot of effort but in the wrong area.

Figure 3. Critical thinking through synthesising credible information

"Coming to this page at the point I have, there is little I can add to what others have said. All the salient points have been listed and relisted with supporting references, some as direct quotes which cannot be argued with, and some in the person's own words

All I can add, I think, is the importance of choosing a subject area that you are interested in, and the willingness to be flexible as and when needed... I've rambled a bit, so I will reiterate my main points.

Interest and Motivation. Flexibility and willingness to change opinion/approach/scope/title.

Risk Analysis.

(This is my own opinion formed from common sense, experience and past reading and therefore cannot be cited.)"

Figure 4. Critical thinking through in depth explanation of a point 


\section{DISCUSSION}

At the end of the course, following an analysis of the results and findings from the experiences of students in using the wiki, it was found that facilitation of critical thinking skills using wiki did happen during the students' individual construction of knowledge. It took place through constructivist approaches where students reflected and synthesised credible information and explained their own ideas in the wiki. From the analysis of wiki pages, it was observed that critical thinking happened through incorporating other's ideas, reflecting, synthesizing credible information and explaining a point in depth. However, a majority of the students still did not really show their critical and analytical skills in interacting, collaborating and discussing socially in the wiki. Therefore, wiki is partially effective as a tool to develop critical thinking skills of students. It can be summarized that critical thinking process happened during students' individual construction of knowledge rather than during social interaction among their peers.

There was a relatively low level of interaction among the peers due to information overload. As such, the students hardly received any individual responses or new ideas from their peers. According to the focus group, it would be ideal to arrange the wiki discussion in a small group that consists of 5-7 students only in order to reduce the amount of time spent for reading and interaction. With a smaller group, it would reduce information overload so that students can focus on reading all the contributions in the same page thus saving time. A tutor could split the group each with their own questions for discussion. It will then be easier for them to discuss and interact together within the group.

Furthermore, in order to promote construction of knowledge online and to facilitate the critical thinking of students through collaborative interaction, students need to challenge their peers and ask intriguing and open ended questions. Asking the right questions is important to keep the discussion going. By doing so, students can articulate their ideas by expanding from their peers' ideas and thus formulate their own ideas and construct their understandings of concepts and theories.

Hence, this shows that keeps the group small and asks triggering questions play a significant part in encouraging interaction and engagement among the students in using the wiki.

\section{CONCLUSIONS}

The study has laid a valuable foundation of knowledge on the status of wiki as a tool in higher education especially in developing and enhancing students' critical thinking skills. This study therefore makes a practical contribution to academics, teachers and tutors and is useful for any training department wanting to move from conventional teaching to teaching online. Many previous researchers discovered that wiki is able to allow collaboration among peers but the results showed that the students were using it as a knowledge repository rather than as a communication tool. The interaction with wiki could be individual or social. Individual interaction happens between the learners and the wiki pages when they are annotating bibliographies and developing the wiki pages and reading the contents of the wiki. Social interaction happens between the peers when they are discussing, commenting on and providing feedback to their peers. The results showed that the facilitation of critical thinking skills happened during individual interactions rather than when social interaction occurs.

The findings reported here have some implications for module leaders especially for those who are lack of knowledge about the potential of wiki in education and ways to design and implement this especially in the facilitation of critical thinking skills. A limitation of the study is the reliance on data from students' learning experiences. It may therefore be relative only to this context within this university and the sample size was very small in relation to the population of students to be generalized. Therefore, future studies could include looking into using similar methods with larger sample sizes and involving more students from various disciplines. This study should be replicated but focus on a range of students from different universities.

\section{ACKNOWLEDGMENT}

The research presented in this article has been supported by University of Derby, UK as part of the PhD research of the author. I would like to express my sincere thanks to the participants of the study for their time and valuable insights.

\section{REFERENCES}

[1] G. Conole and K. Fill, "A Learning Design Toolkit to Create Pedagogically Effective Learning Activities," Journal of Interactive Media in Education, vol. 8, 2005.

[2] D. Newman, C. Johnson, C. Cochrane and B. Webb, “An experiement in group learning technology: evaluating critical thinking in face-to-face and computer-supported seminars" Retrieved September 4, 2008 from School of Finance and Information: http://www.qub.ac.uk/mgt/papers/ccvsem/contents.html/, 1996.

[3] J. infoNet, "Promoting Good Practice, Inspiring Innovation," Retrieved September 8, 2008, from JISC infoNet: Good Practice and Innovation: http://www.jiscinfonet.ac.uk/, 2008.

[4] C. Brahler, I. Quitadarno and E. Johnsons, "Student Critical Thinking is Enhanced by Developing Exercise Prescriptions Using Online Learning Modules," Advances in Physiology Education, vol. 26(3), 2002.

[5] L. Elder, "Diversity: Making Sense of IT Through Critical Thinking," Journal of Quality and Participation, vol. 4, pp. 9-13, 2004.

[6] M. Cubric, "Wiki-supported Blended Learning," University of Hertfordshire Annual Learning and Teaching Conference, 2007.

[7] S. Wheeler, P. Yeomans and D. Wheeler, "The Good, the Bad and the Wiki: Evaluating Student Generated Content For Collaborative Learning," British Journal of Educational Technology, vol. 39 (6), pp. 987-995, 2008. http://dx.doi.org/10.1111/j.1467-8535.2007. 00799.x

[8] M. Boulos, I. Maramba and S. Wheeler, "Wikis, Blogs and Podcasts: A New Generation of Web-based Tools For Virtual Collaborative Clinical Practice and Education," BMC Medical Education, 2006. http://dx.doi.org/10.1186/1472-6920-6-41

[9] A. Desilets and S. Paquet, "Wiki As A Tool For Web-based Collaborative Story Telling in Primary School: A Case Study," In Proceedings of Ed-Media. Montreal, Canada, 2005.

[10] B. McMullin, "Putting The Learning Back Into Learning Technology," In G. O'Neill, S. Moore and B. McMullin, Emerging Issues in the Practice of University Learning and Teaching. Dublin, AISHE, 2005.

[11] M. Doolan, "Collaborative Working: Wiki and the Creation of a Sense of Community," Second International Blended Learning Conference, pp. 72-85, 2007.

[12] 12] C. Coutinho and J. Bottentuit-Junior, "Collaborative Learning Using Wiki: A Pilot Study With Master Students in Educational Technology in Portugal," Proceedings of World Conference on 
PAPER

CAN Wiki Be Used to Facilitate Critical Thinking? : A Qualitative ApProach

Educational Multimedia, Hypermedia and Telecommunications, pp. 1786-1891, 2007.

[13] I. Elgort, A. Smith and J. Toland, "Is Wiki An Effective Platform For Group Course Work?," Australasian Journal of Educational Technology, vol. 24 (2), pp. 195-210, 2008.

[14] F. Lombard, "Empowering Next Generation Learners: Wiki Supported Inquiry Based Learning," European Practise Based And Practitioner Conference on Learning and Instruction. Maastricht, 2007.

[15] L. Anderson and D. Krathwohl, A Taxonomy for Learning, Teaching and Assessing: A Revision of Bloom's Taxonomy of Educational Objectives. New York: Longman, 2001.

[16] K. Parker and J. Chao, "Wiki As A Teaching Tool," Interdisciplinary Journal of Knowledge and Learning Objects, vol. 3, pp. 57$72,2007$.

[17] R. Hall and H. Conboy, "Scoping The Connections Between Emergent Technologies and Pedagogies for Learner Empowerment," The Higher Education Academy: Transforming Higher Education Through Technology-Enhanced Learning. pp. 220-234, 2009.

[18] H. Chen, D. Cannon, J. Gabrio, L.Leifer, G. Toye and T. Bailey, "Using Wikis and Weblogs to Support Reflective Learning in an Introductory Engineering Design Course", Proceeding of the 2005
American Society of Engineering Educational Annual Conference \& Exposition. 2005.

[19] M. Patton, Qualitative Research \& Evaluation Methods. London: Sage, 2002.

[20] N. King, Template Analysis In G. Symon and C. Cassell, Qualitative Methods and Analysis in Organizational Research. London: Sage, 1998.

[21] D. Garrison, T. Anderson and W. Archer, "Critical Inquiry in a Text-Based Environment: Computer Conferencing in Higher Education," The Internet and Higher Education. Vol. 2 (2-3), pp. 87105, 2000. http://dx.doi.org/10.1016/S1096-7516(00)00016-6

\section{AUTHORS}

W. W. Goh is with the School of Computing and IT, Taylor's University, Malaysia. (e-mail: weiwei.goh@taylors.edu.my).

This article is an extended version of a paper presented at IEEE International Conference on Teaching, Assessment and Learning for Engineering 2012 (TALE2012), held 20-23 August 2012, at The Hong Kong Polytechnic University, Hong Kong. Received 11 September 2012. Published as resubmitted by the authors 5 October 2012. 